\title{
Effect of impurities on sintering and conductivity of yttria-stabilized zirconia
}

\author{
M. J. VERKERK* A. J. A. WINNUBST, A. J. BURGGRAAF \\ Twente University of Technology, Department of Chemical Engineering, Laboratory for \\ Inorganic Materials Science, P.O. Box 217, 7500 AE Enschede, The Netherlands
}

The effect of low concentrations of $\mathrm{Fe}_{2} \mathrm{O}_{3}, \mathrm{Al}_{2} \mathrm{O}_{3}$ and $\mathrm{Bi}_{2} \mathrm{O}_{3}$ on the sintering behaviour of $\left(\mathrm{ZrO}_{2}\right)_{0.83}\left(\mathrm{YO}_{1.5}\right)_{0.17}$, made by alkoxide synthesis, has been investigated. The best results are achieved with $\mathrm{Bi}_{2} \mathrm{O}_{3}$ as a sinter agent and a relative density of $95 \%$ is obtained at $1200 \mathrm{~K}$. The effects of these impurities on the electrical conductivity of the bulk and the grain boundaries has been investigated using frequency dispersion analysis $\left(10^{1}-10^{6}\right.$ $\mathrm{Hz}$ ). All investigated impurities have a negative influence on both the bulk and grainboundary conductivity. For $\mathrm{Fe}_{2} \mathrm{O}_{3}$ and $\mathrm{Al}_{2} \mathrm{O}_{3}$ grain-boundary segregation factors of about two are calculated.

\section{Introduction}

The ionic conductivity of ceramic cubic stabilized zirconia depends on the concentration and mobility of oxygen vacancies. At higher concentrations of the stabilizing component $\left(\mathrm{Ca}^{2+}, \mathrm{Y}^{3+}\right.$, lanthanide ions) the concentration of mobile oxygen species is considerably smaller than its nominal value calculated from simple defect chemical considerations. These defect concentrations, that are effective in the conductivity, may be considerably influenced by small amounts of impurities present in the starting oxide powder.

Sometimes, impurities are introduced purposely in order to lower the sintering temperature required for a relative density $>95 \%$ in order to improve the mechanical properties or to regulate the grain size and grain growth. Many studies have been reported in the literature concerning the effects of additives on sintering, e.g. $\mathrm{Fe}_{2} \mathrm{O}_{3}, \mathrm{SiO}_{2}, \mathrm{Al}_{2} \mathrm{O}_{3}$ or $\mathrm{Bi}_{2} \mathrm{O}_{3}$ [1-4]. Radford and Bratton [1] reached a density of $81 \%$ theoretical density when yttriastabilized zirconia was sintered at $1550 \mathrm{~K}$ for $3 \mathrm{~h}$. Introduction of $5 \mathrm{~mol} \% \quad \mathrm{Fe}_{2} \mathrm{O}_{3}$ increases this density by about $10 \%$ to $91.5 \%$, while $1 \mathrm{~mol} \%$ $\mathrm{Al}_{2} \mathrm{O}_{3}$ gives an increase of $6.5 \%$ in relative density. The addition of $1-3 \mathrm{~mol} \% \mathrm{Bi}_{2} \mathrm{O}_{3}$ lowers the sintering temperature from $1970 \mathrm{~K}$ to $1350 \mathrm{~K}$ while the resulting ceramics have a comparable density (92-95\%) and the grain size decreases from $90 \mu \mathrm{m}$ to $5 \mu \mathrm{m}$ [2].

In most cases impurities have a negative effect on the bulk and grain-boundary conductivity [4-6]. If the impurity is uniformly distributed throughout the grain volume, the relative change in bulk and grain-boundary conductivity should be the same [6]. However, it is frequently observed that the grain-boundary conductivity decreases more strongly than that of the bulk.

At low impurity concentrations this is due to the formation of a segregation layer of impurities in the grain boundary. A second phase is generally formed at higher concentrations. In this case the effect on the electrical conductivity depends strongly on the distribution of this second phase, which in many cases concentrates at multiple grain junctions or along grain-boundary edges $[7,8]$. If large concentrations of impurities are present, a second-phase film around the grains can be formed in the case of very good wettability of the grains by this film and a strong influence on the electrical properties is then observed [9].

The influence of $\mathrm{Fe}_{2} \mathrm{O}_{3}$ on the conductivity has been investigated by several authors. The solubility limit of $\mathrm{Fe}_{2} \mathrm{O}_{3}$ in the cubic lattice depends on the thermal history $[3,4]$ and lies

*Present address: Philips Research Laboratories, Eindhoven, The Netherlands. 
in the region of $2-3 \mathrm{~mol} \%$. Wilhelm and Howarth [3] measured the effect of $\mathrm{Fe}_{2} \mathrm{O}_{3}$ on the conductivity of yttria-stabilized zirconia. These authors took measurements at a fixed frequency and, therefore, could not distinguish between bulk and grain-boundary effects. The results of Inozemtsev and Perfil'ev [6] concerning the influence of $\mathrm{Fe}_{2} \mathrm{O}_{3}$ on the grain-boundary conductivity are, in our opinion, contradictory. Bernard [4] performed frequency dispersion measurements on only one iron concentration and found a negative effect of $\mathrm{Fe}_{2} \mathrm{O}_{3}$ on the grainboundary conductivity.

According to Bernard [4], $\mathrm{Al}_{2} \mathrm{O}_{3}$ has a positive effect on the grain-boundary conductivity, but the effect of the grain size was ignored. Inozemtsev and Perfil'ev [6] found that $\mathrm{Al}_{2} \mathrm{O}_{3}$ has a negative effect on the grain-boundary and bulk conductivity. According to Keizer et al. [10], $\mathrm{Bi}_{2} \mathrm{O}_{3}$ has a negative influence on the conductivity but they did not report a detailed study. In a recent study, Verkerk et al. [11] found that the specific grain-boundary conductivity of high purity $\left.\left(\mathrm{ZrO}_{2}\right)_{0.83}(\mathrm{YO})_{1.5}\right)_{0.17}$ is a hundred times lower than that of the bulk.

Therefore we started this study to investigate whether segregation of $\mathrm{Al}_{2} \mathrm{O}_{3}$ and $\mathrm{Fe}_{2} \mathrm{O}_{3}$ could be the cause of this grain-boundary effect and whether introduction of $\mathrm{Bi}_{2} \mathrm{O}_{3}$ results in grainboundary layers with a composition which is different from that of the bulk.

The ionic transport numbers of pure and irondoped yttria-stabilized zirconia are about 1 for the temperature range $(600-900 \mathrm{~K})$ and the atmosphere (air) we used [3]. For bismuth-containing components there is no electronic component found in this temperature range and for oxygen partial pressures $>10^{-6}$ atm [25].

The starting oxide used in this work is a very pure and sinter-reactive powder. In this material impurities are added to a much higher percentage than present in the starting powder. In this way the influence of a specific impurity on sintering and conductivity can be studied.

\section{Experimental details}

The starting $\left(\mathrm{ZrO}_{2}\right)_{0.83}\left(\mathrm{YO}_{1.5}\right)_{0.17}$ powder $(\mathrm{ZY}$ 17) was prepared by the alkoxide method as previously reported [11]. The composition measured by $\mathrm{X}$-ray fluorescence is: 17.0 at $\%$ $\mathrm{Y}, 2.0 \mathrm{wt} \% \mathrm{Hf}$ and $0.01 \mathrm{wt} \% \mathrm{Fe}$. Si $(0.03 \mathrm{wt} \%)$ and $\mathrm{Al}(0.01 \mathrm{wt} \%)$ were measured according to [12]. C ( $0.42 \mathrm{wt} \%)$ was measured after quantitative combustion by the method described in [13]. The concentrations of other impurities are below the detection limit of X-ray fluorescence and emission spectrometry.

The impurities $\left(\mathrm{Bi}_{2} \mathrm{O}_{3}, \mathrm{Fe}_{2} \mathrm{O}_{3}\right.$ and $\left.\mathrm{Al}_{2} \mathrm{O}_{3}\right)$ were added in several ways in order to achieve as homogeneous a distribution as possible. 0.74 and $2.20 \mathrm{~mol} \% \quad \mathrm{Bi}_{2} \mathrm{O}_{3} \quad$ (Merck) were thoroughly mixed with the ZY 17 powder by dry milling. In an additional experiment, $2.20 \mathrm{~mol} \% \mathrm{Bi}_{2} \mathrm{O}_{3}$ was introduced as a solid solution of $\left(\mathrm{Bi}_{2} \mathrm{O}_{3}\right)_{0.75}$ $\left(\mathrm{Y}_{2} \mathrm{O}_{3}\right)_{.25}$ (BY 25) by dry milling. Finally the dopants were added by impregnation. $\mathrm{Bi}_{2} \mathrm{O}_{3}$ $(2.20 \mathrm{~mol} \%)$ was introduced as a solution of $\mathrm{Bi}\left(\mathrm{NO}_{3}\right)_{3}$ (Baker) in $\mathrm{HNO}_{3}$. The iron and aluminium 2.4 pentanedione derivatives (Baker "grade") dissolved in toluene were used for the addition of, respectively, $\mathrm{Fe}_{2} \mathrm{O}_{3}(0.43,0.89$ and $2.10 \mathrm{~mol} \mathrm{\%})$ and $\mathrm{Al}_{2} \mathrm{O}_{3}(0.78 \mathrm{~mol} \%)$ to the $\mathrm{ZY} 17$ powder. All slurries were dried in air at 350 and $390 \mathrm{~K}$ and $0.5 \mathrm{~h}$, respectively, and calcined at $620 \mathrm{~K}$ in air for $0.5 \mathrm{~h}$.

The powders were isostatically pressed at $400 \mathrm{MPa}$ and sintered for $3 \mathrm{~h}$ in a tube furnace. The temperature profile of the furnace during the sintering process is reported in [11]. The densities were measured using the Archimedes technique (in $\mathrm{Hg}$ ). The ceramic structure of polished and thermally etched specimens were investigated using a scanning electron microscope (SEM) type JEOL JSM U3 with an EDAX-unit mounted on it. The grain size was measured according to Mendelson [14]. X-ray diffraction experiments were performed with a Guinier-Simon camera with $\mathrm{Pb}\left(\mathrm{NO}_{3}\right)_{2}$ as the internal standard.

A Solatron 1174 frequency response analyser was used for a.c. conductivity measurements in the frequency range of $10^{1}-10^{6} \mathrm{~Hz}$ (in air). The specimens were machined to the desired size and provided with sputtered platinum electrodes. Further details concerning connections and the frequency dispersion method are described in [11].

\section{Results and discussion}

\subsection{Sintering}

The sintering behaviour of doped and undoped $\mathrm{ZY} 17$ is given in Fig. 1. In comparison with pure ZY 17 all the doped samples showed a decrease in $T_{\mathrm{s}}\left(T_{\mathrm{s}}\right.$ is defined as the temperature at which the relative density is $95 \%$ or more). If $2.20 \mathrm{~mol}$ $\% \mathrm{Bi}_{2} \mathrm{O}_{3}$ is introduced by dry milling, $T_{\mathrm{s}}$ even 


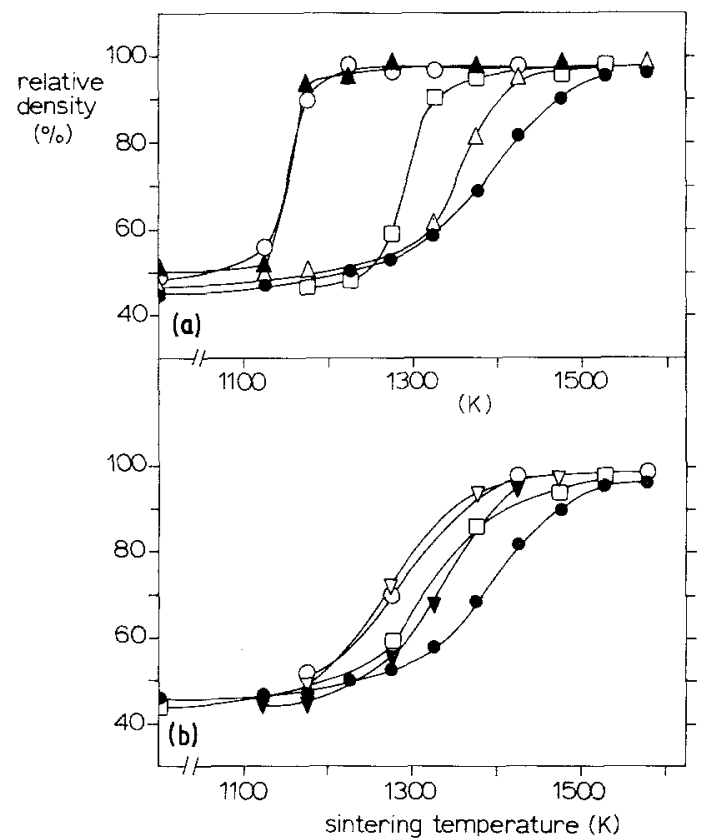

Figure 1 Sintering behaviour of doped and pure $\mathrm{ZY} 17$. -: ZY 17. (a) ם: ZY $17+0.74 \mathrm{~mol} \% \mathrm{Bi}_{2} \mathrm{O}_{3}$. $\mathrm{O}: \mathrm{ZY} 17+$ 2.20 mol\% $\mathrm{Bi}_{2} \mathrm{O}_{3}$ (dry milled as $\mathrm{Bi}_{2} \mathrm{O}_{3}$ ). 4 : $\mathrm{ZY} 17+$ $2.20 \mathrm{~mol} \% \mathrm{Bi}_{2} \mathrm{O}_{3}$ (dry milled as $\mathrm{BY} 25$ ). $\triangle$ : $\mathrm{ZY} 17+$ $2.20 \mathrm{~mol} \% \mathrm{Bi}_{2} \mathrm{O}_{3}$ (impregnated as $\mathrm{Bi}\left(\mathrm{NO}_{3}\right)_{3}$ ). (b) $\square: \mathrm{ZY}$ $17+0.43 \mathrm{~mol} \% \mathrm{Fe}_{2} \mathrm{O}_{3} .0: \mathrm{ZY} 17+0.89 \mathrm{~mol} \% \mathrm{Fe}_{2} \mathrm{O}_{3}$. $\nabla: \mathrm{ZY} 17+2.10 \mathrm{~mol} \% \mathrm{Fe}_{2} \mathrm{O}_{3} . \mathrm{v}: \mathrm{ZY} 17+0.78 \mathrm{~mol} \%$ $\mathrm{Al}_{2} \mathrm{O}_{3}$.

decreases from $1520 \mathrm{~K}$ to $1200 \mathrm{~K}$. In a temperature interval of $50 \mathrm{~K}$ there is a steep increase in density from about $50 \%$ to $90 \%$. The material impregnated with a bismuth nitrate solution has a higher $T_{\mathrm{s}}$ compared with the dry milled materials and exhibits a less steep density increment over a temperature interval of $150 \mathrm{~K}$. Keizer et al. [10] reached a sintering temperature of $1350 \mathrm{~K}$ when $2.4 \mathrm{~mol} \% \mathrm{Bi}_{2} \mathrm{O}_{3}$ was added to $\left(\mathrm{ZrO}_{2}\right)_{0.84}\left(\mathrm{YO}_{1.5}\right)_{0.16}$ using commercial powders as starting materials. We can conclude that $T_{\mathrm{s}}$ decreases more effectively by introducing $\mathrm{Bi}_{2} \mathrm{O}_{3}$ in ultrafine alkoxide powders.

The large decrease in sintering temperature when bismuth oxide is introduced by means of dry milling may be ascribed to a liquid-phase sintering mechanism. This is not, as expected, a simple liquid $\mathrm{Bi}_{2} \mathrm{O}_{3}$ film because $\mathrm{Bi}_{2} \mathrm{O}_{3}$ introduced in the form of $\mathrm{BY} 25$ is as effective as pure $\mathrm{Bi}_{2} \mathrm{O}_{3}$. The melting point of BY 25 is higher than 1250 $\mathrm{K}$ and a possible mechanism that may operate is the formation of a liquid phase by the reaction between BY 25 and ZY 17, e.g. a low-melting $\mathrm{Bi}_{2} \mathrm{O}_{3}-\mathrm{ZrO}_{2}$ solid solution [24]. This will be a point for further investigation. The effect of introducing $\mathrm{Bi}_{2} \mathrm{O}_{3}$ (dry milling or impregnating) on $T_{\mathrm{s}}$ could be ascribed to the difference in initial distribution of $\mathrm{Bi}_{2} \mathrm{O}_{3}$ in the starting material. SEM pictures from sintered specimens of the dry milled materials showed large pores. These pores have the same size as the original crystallite sizes of $\mathrm{Bi}_{2} \mathrm{O}_{3}$ and $\mathrm{BY} 25$ used in the starting material. This gives some support to the suggested liquidphase mechanism during sintering. Large pores were not found in the impregnated material and make the impregnating process of more potential interest for preparing materials for thin walls or thick films. A further investigation on the effect of $\mathrm{Bi}_{2} \mathrm{O}_{3}$ distribution is necessary before any conclusions could be drawn on the sintering mechanism.

The effect of $\mathrm{Fe}_{2} \mathrm{O}_{3}$ and $\mathrm{Al}_{2} \mathrm{O}_{3}$ is less pronounced than that of $\mathrm{Bi}_{2} \mathrm{O}_{3}$. There is a decrease in $T_{\mathrm{s}}$ of about $150 \mathrm{~K}$ by introducing $0.89 \mathrm{~mol} \%$ $\mathrm{Fe}_{2} \mathrm{O}_{3}$. The difference in $T_{\mathrm{s}}$ between the 0.89 mol \% and $2.10 \mathrm{~mol} \% \mathrm{Fe}_{2} \mathrm{O}_{3}$-doped material is negligible (see Fig. 1b) so we can use the lower dope concentration for making sinter-reactive irondoped powders.

The sinter reactivity of the iron-and aluminiumdoped materials is not brought about by a liquid mechansism. This is also assumed by Bernard [4]. As discussed in Section 3.2.2., there is an enrichment of $\mathrm{Fe}_{2} \mathrm{O}_{3}$ and $\mathrm{Al}_{2} \mathrm{O}_{3}$ in the grain boundary. The resulting impurity drag to the grain-boundary impedes grain growth during sintering [15]. Smaller grains, having a larger grain-boundary energy, do have a positive effect on the sintering temperature. The similar sintering behaviour for the samples containing 0.89 and $2.10 \mathrm{~mol} \% \mathrm{Fe}_{2} \mathrm{O}_{3}$ (having the same $T_{\mathrm{s}}$; see above) can be explained by the impurity drag mechanism if the grainboundary concentration of $\mathrm{Fe}_{2} \mathrm{O}_{3}$ during densification is the same for these two samples. Investigations of the grain boundary by means of STEM are in progress.

\subsection{Effect of impurities on the conductivity}

\subsubsection{Characterization of the samples}

Conductivity measurements were performed on samples with the same grain size and density in order to eliminate the influence of these two parameters on the measurements [11]. Table I gives the sintering temperature $\left(T_{\mathrm{s}}\right)$, relative density, grain size $\left(d_{\mathrm{g}}\right)$ and the lattice constant of the cubic 
TABLE I Sintering temperature, density, grain size and lattice constant of pure and doped $\left(\mathrm{ZrO}_{2}\right)_{0.83}\left(\mathrm{YO}_{1.5}\right)_{0.17}$

\begin{tabular}{lllll}
\hline Composition & $T_{\mathrm{S}}(\mathrm{K})$ & Density $(\%)$ & $d_{\mathrm{g}}(\mu \mathrm{m})$ & Lattice constant $\left(10^{-10} \mathrm{~m}\right)$ \\
\hline$\left(\mathrm{ZrO}_{2}\right)_{0.83}\left(\mathrm{YO}_{1.5}\right)_{0.17}$ & 1525 & 98 & 0.7 & $5.1410[12]$ \\
$\quad+0.74 \mathrm{~mol} \% \mathrm{Bi}_{2} \mathrm{O}_{3}$ & 1375 & 96 & 0.7 & $5.1540[10]$ \\
$\quad+2.20 \mathrm{~mol} \% \mathrm{Bi}_{2} \mathrm{O}_{3}$ & 1275 & 97 & 0.8 & $5.1640[10]$ \\
$\quad+0.43 \mathrm{~mol} \% \mathrm{Fe}_{2} \mathrm{O}_{3}$ & 1445 & 96 & 0.7 & $5.1393[10]$ \\
$+0.89 \mathrm{~mol} \% \mathrm{Fe}_{2} \mathrm{O}_{3}$ & 1420 & 98 & 0.7 & $5.1376[10]$ \\
$+2.10 \mathrm{~mol} \% \mathrm{Fe}_{2} \mathrm{O}_{3}$ & 1415 & 96 & 1.0 & $5.1365[6]$ \\
$+0.78 \mathrm{~mol} \% \mathrm{Al}_{2} \mathrm{O}_{3}$ & 1460 & 96 & 0.8 & $5.1408[13]$ \\
\hline
\end{tabular}

phase from the specimens used. Typical microstructures of the bismuth and iron doped material are shown in Fig. 2.

$\mathrm{X}$-ray diffractometry of the $\mathrm{Bi}_{2} \mathrm{O}_{3}$-doped materials showed a fraction of a monoclinic $\mathrm{ZrO}_{2}$ phase. The clusters of smaller grains in Fig. $2 \mathrm{a}$ are ascribed to this monoclinic phase. The method of introducing $\mathrm{Bi}_{2} \mathrm{O}_{3}$ (dry milling or impregnating) had no effect on the cubic lattice constant and the amount of monoclinic phase. This amount was determined from the ratio of intensities of the (111) peak of cubic ZY 17 and the (111) peak of monoclinic $\mathrm{ZrO}_{2}$ using a curve from standard mixtures. From this graph it was calculated that $19 \mathrm{wt} \%$ monoclinic $\mathrm{ZrO}_{2}$ was present in the $0.74 \mathrm{~mol} \%$-doped material sintered at $1375 \mathrm{~K}$. In the same way $38 \mathrm{wt} \%$ monoclinic $\mathrm{ZrO}_{2}$ was found in the $2.20 \mathrm{~mol} \% \mathrm{Bi}_{2} \mathrm{O}_{3}$-doped material sintered at $1275 \mathrm{~K}$.

Assuming the monoclinic phase does not contain yttrium, the composition of the cubic $Z Y$ phase becomes ZY 21 and ZY 27 for the 0.74 and

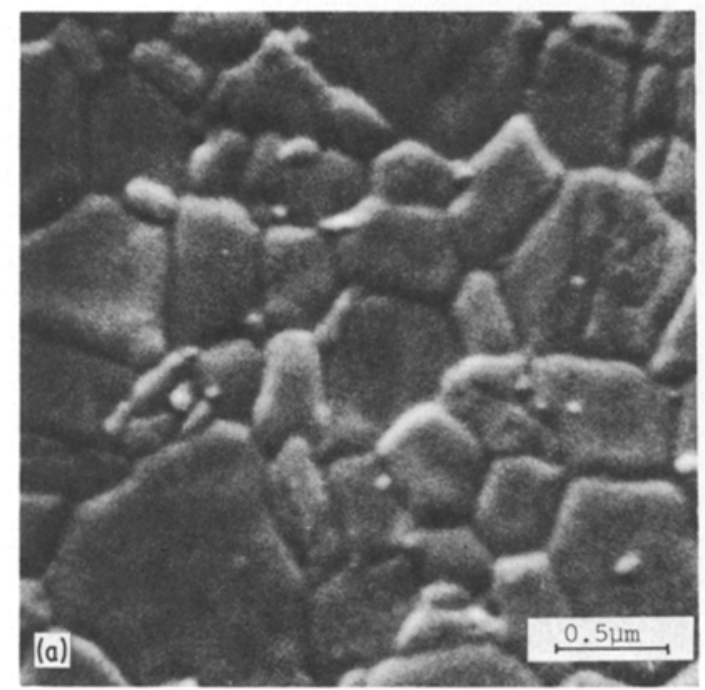

$2.20 \mathrm{~mol} \%$-doped materials, respectively. The cubic lattice constants measured by Baukal and Scheidegger [16] for ZY 17, ZY 21 and ZY 27 are, respectively, $5.1405 \times 10^{-10} \mathrm{~m} ; 5.1470 \times$ $10^{-10} \mathrm{~m}$. The somewhat higher values of the lattice constants found for the $\mathrm{Bi}_{2} \mathrm{O}_{3}$-doped materials (see Table I) could be due to the dissolution in the cubic phase of some bismuth [2], which has a larger ionic radius than $\mathrm{Zr}$ or $\mathrm{Y}$ [17].

By means of $\mathrm{X}$-ray diffractometry, no second phase was found in the $\mathrm{Fe}_{2} \mathrm{O}_{3}$ - and $\mathrm{Al}_{2} \mathrm{O}_{3}$-doped materials used for conductivity measurements. However, EDAX analysis of the $2.10 \mathrm{~mol} \%$ $\mathrm{Fe}_{2} \mathrm{O}_{3}$-doped specimen $\left(T_{\mathrm{s}}=1415 \mathrm{~K}\right)$ showed an iron-rich second phase, of which the amount was too small for detection by X-ray diffractometry.

Fig. 3 shows the lattice constants on the pure and iron-doped ZY 17. From this figure it can be seen that a decrease in the lattice constant appears with increasing amounts of added $\mathrm{Fe}_{2} \mathrm{O}_{3}$. This decrease in lattice constant can be interpreted as a substitution of the smaller iron ions in the fluorite-

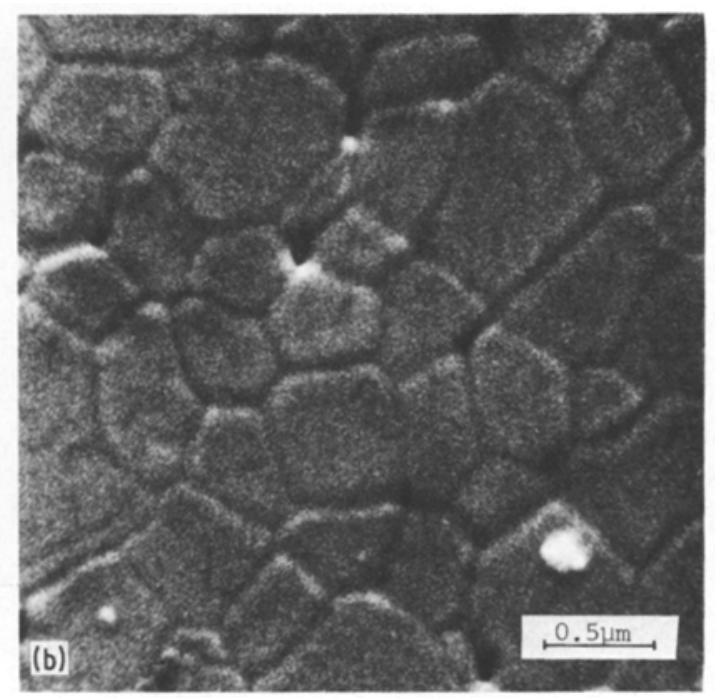

Figure 2 SEM pictures of polished and thermal-etched specimens. (a) $\mathrm{ZY} 17+0.74 \mathrm{~mol}_{\%} \mathrm{Bi}_{2} \mathrm{O}_{3}$. (b) $\mathrm{ZY} 17+0.43$ $\mathrm{mol} \% \mathrm{Fe}_{2} \mathrm{O}_{3}$. 


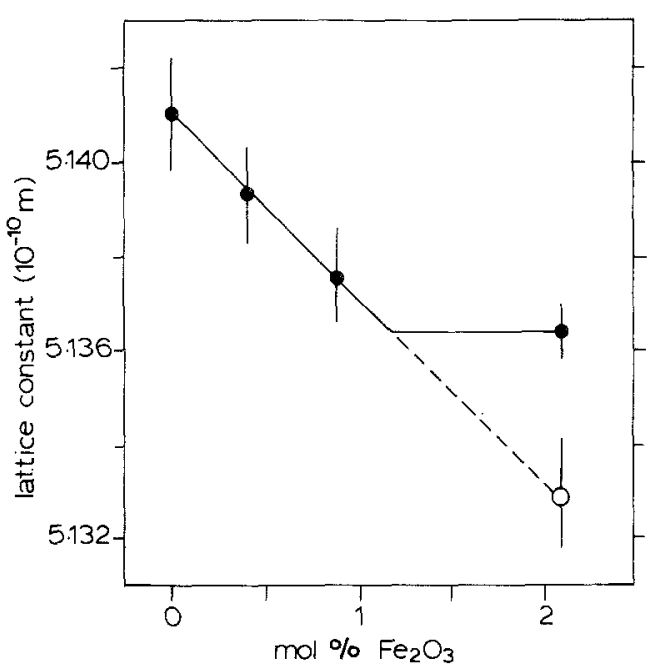

Figure 3 Plot of lattice constant against the concentration of $\mathrm{Fe}_{2} \mathrm{O}_{3}$ added to $\mathrm{ZY} \mathrm{17. \bullet :} \mathrm{samples} \mathrm{cooled} \mathrm{down} \mathrm{slowly}$ to room temperature. $\sigma$ : after quenching from $1475 \mathrm{~K}$.

type lattice of $Z Y 17$. The ionic radii calculated by Shannon and Prewitt [17] of $\mathrm{Fe}^{3+}, \mathrm{Y}^{3+}$ and $\mathrm{Zr}^{4+}$ are, respectively, $0.55 \times 10^{-10} \mathrm{~m} ; 1.015 \times$ $10^{-10} \mathrm{~m}$ and $0.84 \times 10^{-10} \mathrm{~m}$. Consequently, a decreasing value of the unit cell dimension implies an increasing amount of dissolved $\mathrm{Fe}_{2} \mathrm{O}_{3}$.

We can also conclude from this figure that the solubility limit of $\mathrm{Fe}_{2} \mathrm{O}_{3}$ in $\mathrm{Zy} 17$ is $(1.1 \pm 0.1)$ $\mathrm{mol} \%$ of specimens sintered in the region of $1415-1445 \mathrm{~K}$ and slowly cooled to room temperature. Because of this cooling process the temperature at which equilibrium is obtained is not well defined. This "fictive" temperature is anyway lower than the sintering temperature. $2.10 \mathrm{~mol} \% \quad \mathrm{Fe}_{2} \mathrm{O}_{3}$ dissolves completely in the cubic $\mathrm{ZY} 17$ phase at $1475 \mathrm{~K}$ as can be concluded from the lattice constant of the quenched material (see Fig. 3). This shows the strong effect of temperature (increasing solubility with increasing temperature) and cooling process on the dissolution of $\mathrm{Fe}_{2} \mathrm{O}_{3}$.

$\mathrm{X}$-ray diffractometry measurements of the $\mathrm{Al}_{2} \mathrm{O}_{3}$-doped material showed no second phase. The cubic lattice constant of this specimen is almost the same as that of undoped materials (see Table $\mathrm{I}$ ). $\mathrm{Al}^{3+}$ has an ionic radius of $0.53 \times$ $10^{-10} \mathrm{~m}$ [17], which is even smaller than the radius of $\mathrm{Fe}^{3+}$. When $\mathrm{Al}_{2} \mathrm{O}_{3}$ dissolves in the matrix one expects a larger decrease in lattice constant than for the iron-doped material. Therefore we may conclude that a small amount of $\mathrm{Al}_{2} \mathrm{O}_{3}$ can dissolve in the cubic matrix. This agrees with the results of Bernard [4], who found a solubility of $0.1 \mathrm{~mol} \% \quad \mathrm{Al}_{2} \mathrm{O}_{3}$ in $\left(\mathrm{ZrO}_{2}\right)_{0.91}$ $\left(\mathrm{Y}_{2} \mathrm{O}_{3}\right)_{0.09}$ at $1570 \mathrm{~K}$.

\subsubsection{Electrical measurements}

The frequency dispersion measurements were analysed using the equivalent electrical circuit given in Fig. 4a. The interpretation of the grainboundary resistance and the grain-boundary capacity will be discussed below. The complete diagram is given in Fig. 4b. The relevant conductivity and capacity data are determined using the equations:

$$
\begin{gathered}
R_{\mathrm{b}}=R_{1}(A / L) \\
R_{\mathrm{gb}}=\left(R_{2}-R_{1}\right)(A / L) \\
C_{\mathrm{gb}}=\left(1 /\left(R_{2}-R_{1}\right) \omega_{2}\right)(L / A)
\end{gathered}
$$

where $A / L$ is the area/length ratio of the sample and the frequency $\omega=2 \pi f$.

In the brick layer model proposed by Van Dijk and Burggraaf [18] it is assumed that the grain boundary consists of a homogeneous layer with a much higher specific resistivity than that of the bulk material. There is no parallel conduction path along the grain boundaries. This model results in the equivalent electrical circuit shown in Fig. 4a. Pure yttria-stabilized zirconia is well described by this model [11] and it is expected that this will be the case in the majority of the samples reported here (well-developed microstructure, a very small or no second-phase content).

Fig. 5 shows the semicircle due to grain-boundary dispersion for several samples. For all the samples, except ZY 17 with $2.20 \mathrm{~mol} \% \mathrm{Bi}_{2} \mathrm{O}_{3}$, the depression of the semicircles has a value of $7-9^{\circ}$ and does not vary with temperature. The depression of the semicircle for ZY 17 with $2.20 \mathrm{~mol} \% \mathrm{Bi}_{2} \mathrm{O}_{3}$ is about $30^{\circ}$. This means that the equivalent electrical circuit given in Fig. $4 \mathrm{a}$ is not valid. In this case a meaningful interpretation of the complex impedance diagram in terms of a model is difficult. Fig. 6 gives the Arrhenius plots of the bulk and grain-boundary conductivity for several samples. The values of the activation energy, $E_{\mathrm{a}}$, pre-exponential factor $\log \sigma_{0}$ and the grain-boundary capacity $C_{\mathrm{gb}}$ are summarized in Table II. The deviation is given in the $90 \%$ reliability interval.

3.2.2.1. $\mathrm{Fe}_{2} \mathrm{O}_{3}$-doped samples. Fig. 7 gives $\sigma_{\mathrm{b}}, \sigma_{\mathrm{gb}}$ and $\sigma_{\mathrm{b}} / \sigma_{\mathrm{gb}}$ at $773 \mathrm{~K}$ as a function of the iron content. Taking into account the solubility limit 
(a)

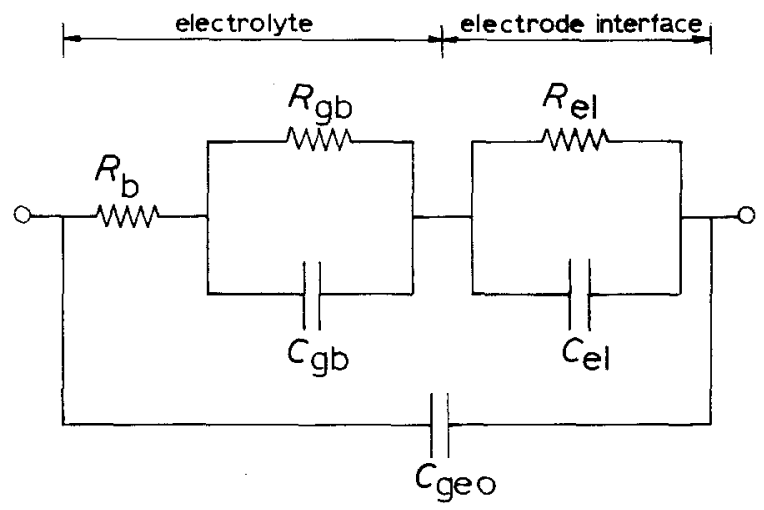

Figure 4 (a) The total equivalent electrical circuit, originally proposed by Bauerle [20]. (b) Complex impedance diagram representing the circuit shown in (a). $R_{\mathrm{b}}$, resistance of the bulk. $R_{\mathrm{gb}}$, resistance of the grain boundary. $R_{\mathrm{el}}$, resistance of the electrode. $C_{\text {geo }}$, capacity of the bulk. $C_{\text {gb }}$, capacity of the grain boundary. $C_{\mathrm{el}}$, capacity of the electrode.

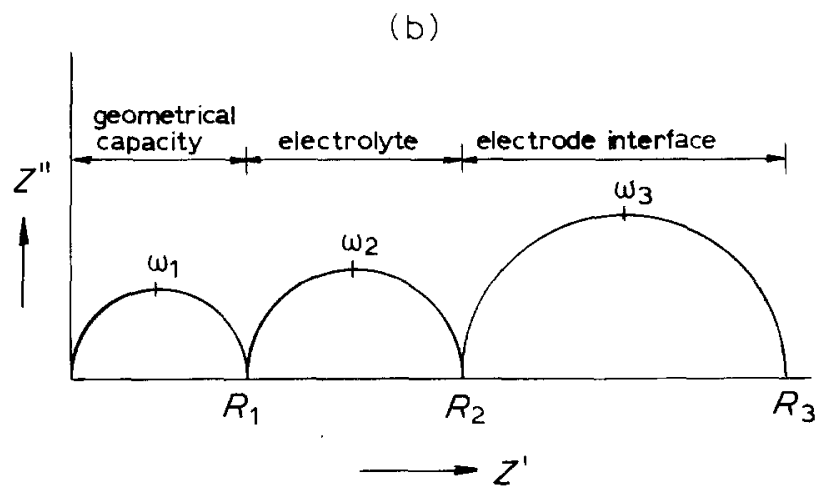

(Section 3.2.1.) the bulk conductivity decreases linearly with increasing iron content and $E_{\mathrm{a}}(\mathrm{b})$ does not change. The grain-boundary conductivity decreases more strongly with increasing iron content than the bulk conductivity, as clearly shown by the increase of $\sigma_{\mathrm{b}} / \sigma_{\mathrm{gb}}$ with increasing iron content. $E_{\mathrm{a}}(\mathrm{gb})$ also increases slightly with increasing iron content (see Table II). These data point to an enrichment of iron in the grain boundaries and will now be discussed.

Second-phase particles were only found for the sample with $2.10 \mathrm{~mol} \% \mathrm{Fe}_{2} \mathrm{O}_{3}$ (Section 3.2.1.). It was shown $[7,8]$ that small amounts of second phase in most ceramic systems are concentrated at multiple grain junctions, either in the form of pockets or sometimes interconnected along threegrain edges. If we assume that this situation holds for the materials studied here, then a negligible part of the grain-boundary surface is covered with this second phase and constriction of the current will be of minor importance. This is confirmed by the continuity of $\sigma_{\mathrm{gb}}$ and $E_{\mathrm{a}}(\mathrm{gb})$ across the solubility limit (see Fig. 7 and Table II). Hence, the brick layer model will be used for the irondoped samples.
In this model the following relations for $C_{\mathrm{gb}}$ and $\sigma_{\mathrm{gb}}$ were derived [19]:

$$
\begin{gathered}
C_{\mathrm{gb}}=\epsilon_{0} \epsilon_{\mathrm{r}}(\mathrm{gb}) \frac{d_{\mathrm{g}}}{\delta_{\mathrm{gb}}} \\
\sigma_{\mathrm{gb}}=\sigma_{\mathrm{gb}}^{\mathrm{sp}} \frac{d_{\mathrm{g}}}{\delta_{\mathrm{gb}}}
\end{gathered}
$$

where $\epsilon_{\mathrm{r}}(\mathrm{gb})$ is the permittivity of the grainboundary material, $\delta_{\mathrm{gb}}$ is the grain-boundary thickness, and $\sigma_{\mathrm{gb}}^{\mathrm{sp}}$ is the grain-boundary conductivity corrected for the dimensions of the grain boundary. Within experimental error, $C_{\mathrm{gb}}$ is not influenced by the iron content and $\delta_{\mathrm{gb}}$ can be calculated from Equation 5. A reasonable value for $\epsilon_{\mathrm{r}}(\mathrm{gb})$ is the permittivity of the bulk material. Using $\epsilon=70[18,21] \delta_{\mathrm{gb}}$ is estimated to be $(4.2 \pm 0.4) \mathrm{nm}$. Applying Equation 6 we can conclude that the decrease of $\sigma_{\mathrm{gb}}$ as a function of the iron content can be ascribed to a decrease in the specific grain-boundary conductivity, $\sigma_{\mathrm{gb}}^{\mathrm{sp}}$. For pure ZY 17 and the sample doped with 2.10 mol $\% \mathrm{Fe}_{2} \mathrm{O}_{3}$ at $773 \mathrm{~K}$, $\sigma_{\mathrm{gb}}^{\mathrm{sp}}$ values are $8.4 \times$ $10^{-4}$ and $1.8 \times 10^{-4} \Omega^{-1} \mathrm{~m}^{-1}$, respectively, and 


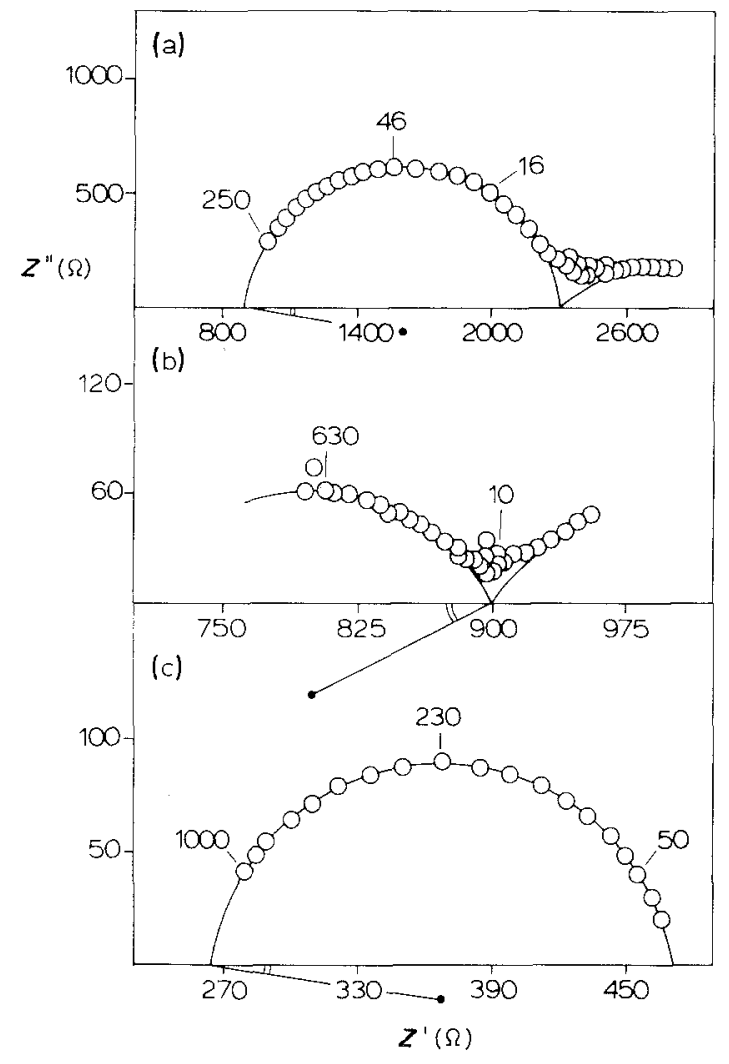

Figure 5 Complex impedance diagrams in air. The frequency is given in $\mathrm{kHz}$. ZY 17 with (a) $0.74 \mathrm{~mol} \% \mathrm{Bi}_{2} \mathrm{O}_{3}$ at $765 \mathrm{~K}$; (b) $2.20 \mathrm{~mol} \% \mathrm{Bi}_{2} \mathrm{O}_{3}$ at $800 \mathrm{~K}$; and (c) 0.43 $\mathrm{mol} \% \mathrm{Fe}_{2} \mathrm{O}_{3}$ at $776 \mathrm{~K}$.

$\sigma_{\mathrm{b}} / \sigma_{\mathrm{gb}}^{\mathrm{sp}}$ values are 105 and 195 , respectively. ${ }^{*}$ The stronger decrease of $\sigma_{\mathrm{gb}}^{\mathrm{sp}}$ with the iron content in comparison with that of $\sigma_{\mathrm{b}}$ can be explained in terms of an enrichment of iron in the grain boundary.

A segregation factor of about 2 was calculated, assuming that the mechanism by which iron influences the conductivity is the same for the bulk and for the grain boundary. Bernard's [4] data show the same features. On the basis of $\sigma_{\mathrm{gb}}$ found in this study we calculated for $\left(\mathrm{ZrO}_{2}\right)_{0.831}\left(\mathrm{YO}_{1.5}\right)_{0.169}$ and $\left(\mathrm{ZrO}_{2}\right)_{0.831}\left(\mathrm{YO}_{1.5}\right)_{0.150}\left(\mathrm{FeO}_{1.5}\right)_{0.019}$ at $773 \mathrm{~K}$ and $d_{\mathrm{g}}=3 \mu \mathrm{m}, \sigma_{\mathrm{b}} / \sigma_{\mathrm{sp}}^{\mathrm{gb}}$ values of 310 and 920 , respectively, resulting in a segregation factor of about 3 . The driving force for this enrichment of iron may be a decrease of the strain energy because the ionic radius of $\mathrm{Fe}^{3+}$ is much smaller than that of $\mathrm{Zr}^{4+}$ and $\mathrm{Y}^{3+}$.

\subsubsection{2. $\mathrm{Al}_{2} \mathrm{O}_{3}$-doped sample. As shown in Section} 3.2.1. the solubility of $\mathrm{Al}_{2} \mathrm{O}_{3}$ in $\mathrm{ZY} 17$ is very

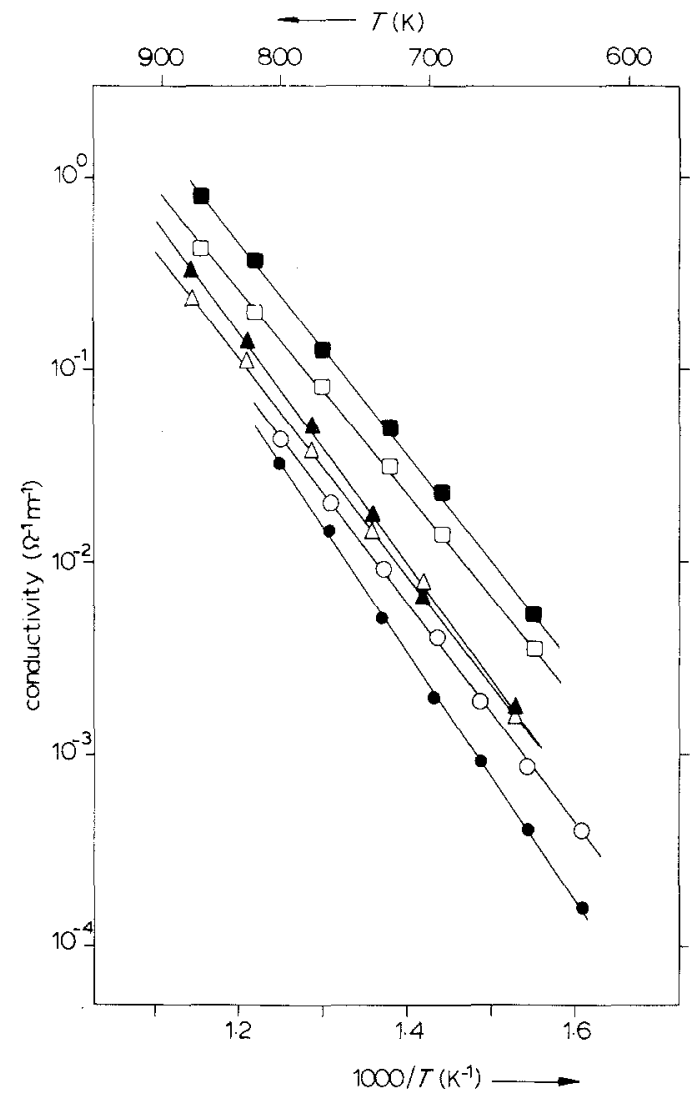

Figure 6 Bulk (open points) and grain-boundary (closed points) conductivity of several samples: ZY 17 (), ZY 17 with $2.1 \mathrm{~mol} \% \mathrm{Fe}_{2} \mathrm{O}_{3}(\triangle)$ and $\mathrm{ZY} 17$ with $0.74 \mathrm{~mol} \%$ $\mathrm{Bi}_{2} \mathrm{O}_{3}(\mathrm{o})$.

small. Some second-phase particles will be present. As discussed above for the sample containing $2.10 \mathrm{~mol} \% \mathrm{Fe}_{2} \mathrm{O}_{3}$ constriction will play only a role of minor importance. In comparison with the pure sample $\sigma_{\mathrm{b}}$ decreases from $9.0 \times 10^{-2}$ to $7.7 \times 10^{-2} \Omega^{-1} \mathrm{~m}^{-1}$ and $\sigma_{\mathrm{gb}}$ from $14.2 \times 10^{-2}$ to $9.8 \times 10^{-2} \Omega^{-1} \mathrm{~m}^{-1}$ (773 K). The $\mathrm{Al}_{2} \mathrm{O}_{3}$-dopant does not influence $E_{\mathrm{a}}(\mathrm{b})$ and $C_{\mathrm{gb}}$ whereas $E_{\mathrm{a}}(\mathrm{gb})$ is significantly increased. With $\delta_{\mathrm{gb}}=4.2 \mathrm{~nm}$ then $\sigma_{\mathrm{gb}}^{\mathrm{sp}}$ is calculated as $4.6 \times 10^{-4} \Omega^{-1}$ at $773 \mathrm{~K}$. For the pure sample and the $\mathrm{Al}_{2} \mathrm{O}_{3}$-doped sample, the values for $\sigma_{\mathrm{b}} / \sigma_{\mathrm{gb}}^{\mathrm{sp}}$ are 105 and 167 , respectively. Bernard [4] found that $\sigma_{\mathrm{b}}, E_{\mathrm{a}}(\mathrm{b})$ and $E_{\mathrm{a}}(\mathrm{gb})$ did not change as a function of the $\mathrm{Al}_{2} \mathrm{O}_{3}$ content. This is not in conflict with our measurements because for Bernard's samples the $\left(\mathrm{YO}_{1.5}+\mathrm{Al}_{1.5}\right)$ concentration is kept constant. On the basis of $\delta_{\mathrm{gb}}=4.2 \mathrm{~nm}$ we calculated for Bernard's samples [4] with $d_{\mathrm{g}}=4.5 \mu \mathrm{m}$ and $T=773 \mathrm{~K}$ : the values of $\sigma_{\mathrm{b}} / \sigma_{\mathrm{gb}}^{\mathrm{sp}}$ are 430 and $585 \pm 90$ for $\left(\mathrm{ZrO}_{2}\right)_{0.831}$

*This ratio is different from the ratio given in Fig. 7. In Fig. $7 \sigma_{\mathrm{gb}}$ is not corrected for grain-boundary dimensions. 
TABLE II Activation energies and $\log a_{0}$ for the bulk and grain-boundary conductivity for ZY 17 and doped ZY 17

\begin{tabular}{|c|c|c|c|c|c|}
\hline Composition & $\begin{array}{l}E_{\mathrm{a}}(\mathrm{b}) \\
\left(\mathrm{kJ} \mathrm{mol}^{-1}\right)\end{array}$ & $\begin{array}{l}\log \sigma_{0}(\mathrm{~b}) \\
\left(\Omega^{-1} \mathrm{~m}^{-1}\right)\end{array}$ & $\begin{array}{l}E_{\mathrm{a}}(\mathrm{gb}) \\
\left(\mathrm{kJ} \mathrm{mol}{ }^{-1}\right)\end{array}$ & $\begin{array}{l}\log \sigma_{0}(\mathrm{gb}) \\
\left(\Omega^{-1} \mathrm{~m}^{-1}\right)\end{array}$ & $\begin{array}{l}C_{\mathrm{gb}} \\
\left(10^{-7} \mathrm{~F} \mathrm{~m}^{-1}\right)\end{array}$ \\
\hline$\left(\mathrm{ZrO}_{2}\right)_{0.83}\left(\mathrm{YO}_{1.5}\right)_{0.17}$ & $106 \pm 2$ & $6.11 \pm 0.17$ & $107 \pm 2$ & $6.36 \pm 0.13$ & $1.14 \pm 0.18$ \\
\hline$+0.74 \mathrm{~mol} \% \mathrm{Bi}_{2} \mathrm{O}_{3}$ & $110 \pm 3$ & $5.82 \pm 0.19$ & $123 \pm 2$ & $6.60 \pm 0.16$ & $0.46 \pm 0.06$ \\
\hline$+0.43 \mathrm{~mol} \% \mathrm{Fe}_{2} \mathrm{O}_{3}$ & $104 \pm 4$ & $5.87 \pm 0.26$ & $109 \pm 7$ & $6.39 \pm 0.43$ & $1.07 \pm 0.18$ \\
\hline$+0.89 \mathrm{~mol} \% \mathrm{Fe}_{2} \mathrm{O}_{3}$ & $101 \pm 5$ & $5.60 \pm 0.36$ & $114 \pm 9$ & $6.58 \pm 0.72$ & $0.90 \pm 0.20$ \\
\hline$+2.10 \mathrm{~mol} \% \mathrm{Fe}_{2} \mathrm{O}_{3}$ & $107 \pm 3$ & $5.81 \pm 0.18$ & $116 \pm 3$ & $6.44 \pm 0.28$ & $1.02 \pm 0.18$ \\
\hline$+0.78 \mathrm{~mol} \% \mathrm{Al}_{2} \mathrm{O}_{3}$ & $105 \pm 4$ & $5.73 \pm 0.34$ & $125 \pm 5$ & $7.47 \pm 0.35$ & $1.24 \pm 0.32$ \\
\hline
\end{tabular}

$\left(\mathrm{YO}_{1.5}\right)_{0.169}$ and $\left(\mathrm{ZrO}_{2}\right)_{0.831}\left(\mathrm{YO}_{1.5}\right)_{0.169-x}\left(\mathrm{Al}_{1.5}\right)_{x}$ with $x=0.008 \sim 0.031$, respectively. We can now conclude that the grain boundary is slightly enriched with aluminium oxide. This cannot, however, explain the increase in the activation energy of the grain boundary, because in this case the same effect would occur for the bulk activation energy (which is not observed). Obviously the mechanism by which the bulk and the grainboundary conductivity are affected by the impurity is different.

We can conclude that the large effect of grain boundaries on the conductivity of the pure material $\left(\sigma_{\mathrm{b}} / \sigma_{\mathrm{gb}}^{\mathrm{sp}}=105\right.$ at $\left.773 \mathrm{~K}\right)$ cannot be explained by impurity segregation of $\mathrm{Fe}^{3+}$ and/or $\mathrm{Al}^{3+}$ only.

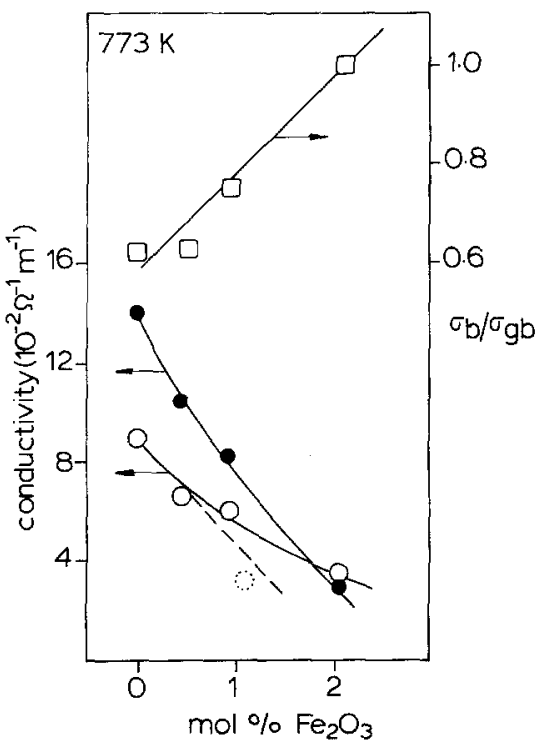

Figure 7 Bulk conductivity (o), grain-boundary conductivity $(\bullet)$ and $\sigma_{b} / \sigma_{g b}(\square)$ as a function of the iron content. Dashed line and dashed point give $\sigma_{\mathrm{b}}$ after correction for the solubility limit (see text). The grain-boundary conductivity for the sample containing $2.10 \mathrm{~mol} \% \mathrm{Fe}_{2} \mathrm{O}_{3}$ is corrected for the grain size effect to $d_{\mathrm{g}}=0.7 \mu \mathrm{m}$ according to Equation 6.
3.2.2.3. $\mathrm{Bi}_{2} \mathrm{O}_{3}$-doped samples. The bulk conductivity of the sample with $0.74 \mathrm{~mol}^{2} \mathrm{Bi}_{2} \mathrm{O}_{3}$ is $2.39 \mathrm{x}$ $10^{-2} \Omega^{-1} \mathrm{~m}^{-1}$ at $773 \mathrm{~K}$, this is a factor 3.8 smaller than that for $\mathrm{ZY} 17$. The decrease in the bulk conductivity can be mainly ascribed to the increase in the yttrium content. The bulk composition of this sample is ZY 21, as discussed in Section 3.2.1. The conductivity of ZY 21 is a factor 2.8 lower than that for $\mathrm{ZY} 17$, as calculated by extrapolating from the data of Inozemtsev and Perfil'ev [20]. However, according to these authors, $E_{\mathrm{a}}(\mathrm{b})$ should increase by $20 \mathrm{~kJ} \mathrm{~mol}^{-1}$, whereas we find an increase of $4 \mathrm{~kJ} \mathrm{~mol}^{-1}$. This difference may be explained in the following way. It was shown by Keizer et al. [10] that some $\mathrm{Bi}_{2} \mathrm{O}_{3}$ is dissolved in the main phase. The $\mathrm{Bi}^{3+}$ ion has a high polarizability. Introduction of such an ion in a tetrahedron plane results in a more negative value of the polarization energy. Therefore, the energy during passage through the tetrahedraon plane is decreased, resulting in a lower activation energy [23].

The grain-boundary conductivity of the sample with $0.74 \mathrm{~mol}_{\%} \mathrm{Bi}_{2} \mathrm{O}_{3}$ is $1.61 \times 10^{-2} \Omega^{-1} \mathrm{~m}^{-1}$ at $773 \mathrm{~K}$ and this is a factor 8.8 smaller than that for ZY 17. In the sample a large amount of secondphase particles are present on the grain boundaries (Section 3.2.1.). Therefore, constriction of the current at the grain boundaries can be expected and partly accounts for the measured effect. However, the increase in the activation energy of the grain boundary with $16 \mathrm{~kJ} \mathrm{~mol}^{-1}$ cannot be explained in this way. ${ }^{*}$

As discussed above, no higher activation energy can be expected if the grain-boundary layer is enriched with bismuth ions. Therefore, enrichment of yttrium ions is most probable. Preliminary Auger experiments on a fractured surface of $\mathrm{ZY}$ 17 with 0.74 and $2.20 \mathrm{~mol} \% \mathrm{Bi}_{2} \mathrm{O}_{3}$ showed that the grain boundary is indeed enriched with $\mathrm{Y}^{3+}$. Further studies are now being performed.

*According to Bauerle's [19] constriction model, $E_{\mathrm{a}}(\mathrm{b})$ should be equal to $E_{\mathrm{a}}(\mathrm{gb})$. 


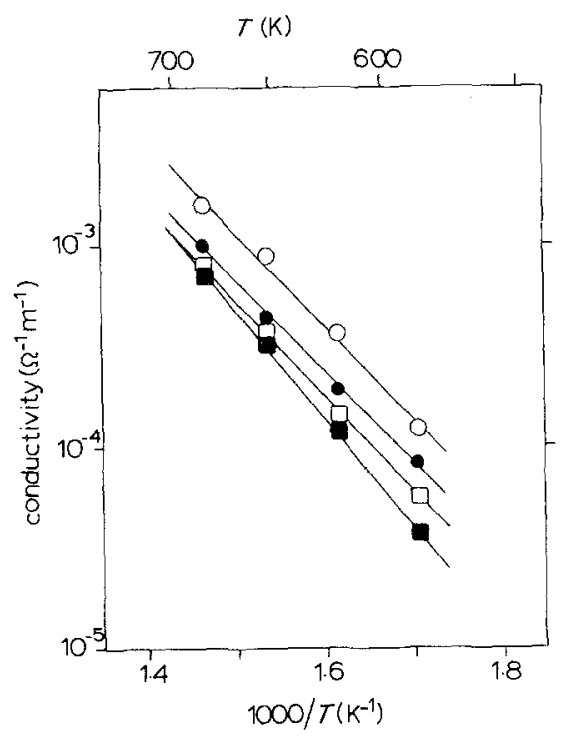

Figure 8 Conductivity of $\mathrm{ZY} 17$ with $0.74 \mathrm{~mol} \% \mathrm{Bi}_{2} \mathrm{O}_{3}$ (0) and of $\mathrm{ZY} 17$ with $2.20 \mathrm{~mol} \% \mathrm{Bi}_{2} \mathrm{O}_{3}$ (口) at $1 \mathrm{kHz}$ $(\bullet \bullet)$ and at $10 \mathrm{kHz}(\circ \mathrm{O})$.

As discussed above, the interpretation of the frequency dispersion diagrams of $Z Y 17$ with $2.20 \mathrm{~mol}^{\%} \mathrm{Bi}_{2} \mathrm{O}_{3}$ is not possible using the equivalent electrical circuit shown in Fig. 4a. Some information can be obtained from conductivity data at a fixed frequency. The conductivity at 1 and $10 \mathrm{kHz}$, as shown in Fig. 8 , is lower for the sample containing $2.20 \mathrm{~mol} \% \mathrm{Bi}_{2} \mathrm{O}_{3}$ than for the sample containing $0.74 \mathrm{~mol} \% \mathrm{Bi}_{2} \mathrm{O}_{3}$. This is quite plausible because the sample with $2.20 \mathrm{~mol}$ $\% \mathrm{Bi}_{2} \mathrm{O}_{3}$ contains more second phase and the bulk has a higher yttrium content (Section 3.2.1.).

\section{Conclusions}

1. (a) Introduction of $0.9 \mathrm{~mol} \% \mathrm{Fe}_{2} \mathrm{O}_{3}$ in $\mathrm{ZY} 17$ reduces the temperature $T_{\mathrm{s}}$ at which the relative density is $95 \%$ or more by $150 \mathrm{~K}$. A larger amount of $\mathrm{Fe}_{2} \mathrm{O}_{3}$ does not lower $T_{\mathrm{s}}$ significantly.

(b) The conductivity of the bulk and the grainboundary decreases linearly with increasing iron content. A maximum grain-boundary enrichment factor of $2 \sim 3$ was calculated for iron.

2. Introduction of $0.78 \mathrm{~mol} \% \quad \mathrm{Al}_{2} \mathrm{O}_{3}$ reduces $T_{\mathrm{s}}$ by $100 \mathrm{~K} . \mathrm{Al}_{2} \mathrm{O}_{3}$ does increase the activation energy of the grain boundary by $20 \mathrm{~kJ} \mathrm{~mol}^{-1}$ and decreases the bulk and grain-boundary conductivity. It was calculated that the grain boundary is only slightly enriched with $\mathrm{Al}_{2} \mathrm{O}_{3}$.

3. In the pure material the specific conductivity of the grain boundary is 100 times lower than that of the bulk. This effect cannot be ascribed to the low concentrations of $\mathrm{Fe}_{2} \mathrm{O}_{3}$ and $\mathrm{Al}_{2} \mathrm{O}_{3}$ present in the pure material.

4. Introduction of 0.74 and $2.20 \mathrm{~mol} \% \mathrm{Bi}_{2} \mathrm{O}_{3}$ decreases $T_{\mathrm{s}}$ by 150 and $325 \mathrm{~K}$, respectively. A large amount of $\mathrm{ZrO}_{2}$-rich second phase is present at the boundary, while bulk and grain boundary are probably yttrium enriched. The result is a strong decrease of the conductivity, which is more pronounced than that of $\mathrm{Fe}_{2} \mathrm{O}_{3}$ and $\mathrm{Al}_{2} \mathrm{O}_{3}$.

\section{Acknowledgements}

We would like to thank Mr J.van der Beek for preparation of the samples, $\mathrm{Mr} \mathrm{H}$. Kruidhof for the chemical analysis and Mr J. Boeysma for performing the Guinier experiments. Financial assistance from Philips N.V. (Elcoma) is gratefully acknowledged.

\section{References}

1. K. C. RADFORD and R. J. BRATTON, J. Mater. Sci. 14 (1979) 59.

2. K. KEIZER, M. J. VERKERK and A.J.BURGGRAAF, Ceramurgia Int. 5 (1979) 143.

3. R. V. WILHELM and D. S. HOWARTH, Ceram. Bull. 58 (1979) 229.

4. H. BERNARD, PhD thesis, Grenoble (1980).

5. K. C. RADFORD and R. J. BRATTON, J. Mater. Sci. 14 (1979) 66.

6. M. V.INOZEMTSEV and M. V. PERFIL'EV, Elektrokhimiya 11 (1975) 1031.

7. P. F. BONGERS and P.E.C. FRANKEN, $A d v$. Ceram. 1 (1981) 38.

8. W. D. KINGERY, J. Amer. Ceram. Soc. 57 (1974) 74.

9. N. M. BEEKMANS and L. HEYNE, Electochim. Acta 21 (1976) 303.

10. K. KEIZER, A. J. BURGGRAAF and G. de WITH, J. Mater. Sci 17 (1982) 1095

11. M. J, VERKERK, B. J. MIDDELHUIS and A. J. BURGGRAAF, Solid State Ionics 6 (1982) 159.

12. H. KRUIDHOF, Anal. Chim. Acta 99 (1978) 193.

13. Dutch Normalization Institute NEN, 3130 (1968).

14. M. I. MENDELSON, J. Amer. Ceram. Soc. 52 (1969) 443.

15. R. J. BROOK, "Treatise on Materials Science and Technology", edited by F.J.Wang, Vol. 9, (Academic Press, New York, 1976) pp. 331-63.

16. W. BAUKAL and R. J. SCHEIDEGGER, Ber. Dt. Keram Ges. 45 (1968) 610.

17. R. D. SHANNON and C. T. PREWITT, Acta Cryst. B25 (1969) 925.

18. T. VAN DIJK and A. J. BURGgRAFF, Phys. Stat. Sol. (a) 63 (1981) 229.

19. J. E. BAUERLE, J. Phys. Chem. Solids 30 (1969) 2657.

20. M. V. INOZEMTSEV and M. V. PERFIL'EV, Elektrohimiya 12 (1976) 1236.

21. W. N. LAWLESS, Phys. Rev. B 22 (1980) 3122.

22. E. SCHOULER, PhD thesis, Grenoble (1980). 
23. M. J. VERKERK, G. M. H. VAN DE VELDE, R. B. HELMDOLDT and A. J. BURGGRAAF, J. Phys Chem. Solids 43 (1982) to be published.

24. E. M. LEVIN and R. S. ROTH, J. Res. Nat. Bur. Stand. 68A (1964) 197.
25. T. TAKAHASHI, H. IWAHARA and T. ARAO, $J$. Appl. Electrochem. 5 (1975) 187.

Received 24 November 1981 and accepted 15 March 1982 